American Journal of Applied Sciences 7 (10): 1426-1431, 2010

ISSN 1546-9239

(C) 2010 Science Publications

\title{
Empirical Validation of Daylight Simulation Tool with Physical Model Measurement
}

\author{
${ }^{1}$ Yaik-Wah Lim, ${ }^{2}$ Mohd. Hamdan Ahmad and ${ }^{1}$ Dilshan Remaz Ossen \\ ${ }^{1}$ Department of Architecture, Faculty of Built Environment, \\ ${ }^{2}$ Faculty of Built Environment, Institute Sultan Iskandar of Urban Habitat and Highrise, \\ University Technology Malaysia, Malaysia
}

\begin{abstract}
Problem statement: In recent years, daylighting simulation tools have been increasingly used by many architects, engineers and researchers to evaluate the day lighting performances of building design. Most of these tools employ CIE sky models for simulation. However, the accuracy and applicability of these tools for tropical sky are doubtable. The aim of this study was to validate the computer simulated result with scaled physical model results measured under real tropical sky. Approach: Daylighting model was constructed using scaled physical model to be tested under real sky measurement. The same model was configured in Desktop Radiance 2.0 to perform day lighting simulation experiments. All the measurements were carried out under intermediate and overcast tropical sky conditions in Malaysia; while related CIE sky conditions were used for simulations. Results: Due to the CIE sky conditions are very dissimilar from the actual tropical sky; simulated absolute value results such as external illuminance, absolute work plane illuminance and surface luminance recorded high mean differences from the measured results, with 81.63; 71.06 and $49.71 \%$, respectively. However, relative ratios such as Daylight Factor (DF) yielded mean difference of $26.06 \%$ and luminance ratio was $29.75 \%$ only. The average mean difference was $44.37 \%$. Conclusion/Recommendations: To compare the performances, relative ratios such as DF and luminance ratio showed better accuracies. For future research, validation on other parameters can be performed such as orientations, angle of the overhang, glazing, window sizes, colors, environment settings and electric lighting.
\end{abstract}

Key word: Daylight, simulation, desktop radiance, physical model

\section{INTRODUCTION}

The developments in windows technologies have provided new possibilities for architects to utilize daylight for indoor climate and visual comfort (Dubois, 2001; Arasteh et al., 2003). Daylight not only contributes to energy saving for building lighting, but also provides a healthy and comfort environment for the occupants. Since 30-50 percent of energy used in a commercial building is to illuminate the interior spaces, daylight can reduce the dependency on electrical lighting (Robbins, 1986). For the same amount of light, daylight is more efficient at providing light in comparison to electric lighting and producing less heat. Thus, daylight has become a commonly used design strategy for better building performance. However, in tropical climate, the abundance of daylight has not yet been utilized (Ossen et al., 2005).
Since last 30 years, increasing numbers of daylight simulation tools are made available (Ander, 2003; Loutzenhiser et al., 2007; Xia et al., 2008). Pre-design stage is the best opportunities for improving a building's energy performance. During this stage, simulation tools are useful to predict and improve building daylight design (Lim et al., 2008). Besides, simulation tools are also utilized to assist in the lighting and shading system control in buildings (Mahdavi, 2008).

Radiance is an advance lighting analysis and visualization tool for a UNIX environment. Desktop Radiance 2.0 is a more user-friendly derivative of Radiance that runs under the Windows operating system from within AutoCAD 14 using pull-down menus. However, not all of the key operating features in standard Radiance are available in Desktop Radiance 2.0 (Mistrick, 2000).

Corresponding Author: Yaik-Wah Lim, Faculty of Built Environment, Institute Sultan Iskandar of Urban Habitat and Highrise, University Technology Malaysia, Malaysia 
Desktop Radiance 2.0 uses International Commission on Illumination (CIE) sky models for simulation: CIE clear sky, CIE intermediate sky and CIE overcast sky and uniform sky. Sky model influences the distribution and amount of external illuminance to further predict the indoor illuminance. Thus, the accuracy of using CIE skies to simulate buildings under tropical sky is debatable (ZainAhmed et al., 2002; Linhart et al., 2010).

The aim of this study is to validate the simulated and measured results using Desktop Radiance 2.0 to the result of the scaled physical model experiment under real tropical sky. Besides, it is also to test the daylight performance of the simulation tool for various variables.

\section{MATERIALS AND METHODS}

Model configuration: A room with a single aperture was developed according to the geometries and characteristics of Malaysian office (Ossen et al., 2005). As shown in Fig. 1, the physical model of an office room was constructed using $12 \mathrm{~mm}$ thick plywood with 1: 2 scales. The geometrical configurations were as shown in Fig. 2. An aperture without glazing was constructed on the east external wall. The Window-to-Wall Ratio (WWR) of the aperture was $50 \%$. The whole model was painted in white. The test site was located at an open car park at Faculty of Built Environment, University Technology Malaysia, Skudai, Johor, Malaysia. The same model configuration was developed in Desktop Radiance 2.0 for the simulation study. The location used for the simulation was Johor Bahru, with latitude $1^{\circ} 28$, 0'N and longitude $103^{\circ} 45^{\prime}$ ' ${ }^{\prime \prime} \mathrm{E}$.

Limitation: The surrounding environment of the site may affect the daylight performances. Thus, the reflectance value of the surrounding environment and the model surface were measured and modeled. The average reflectance value for the tar surface of the car park was 0.05; whereas the white painted model surface was 0.87 . However, there were vegetations adjacent to the physical model not modeled for simulation. Hence, the effect in term of providing shade was negligible.
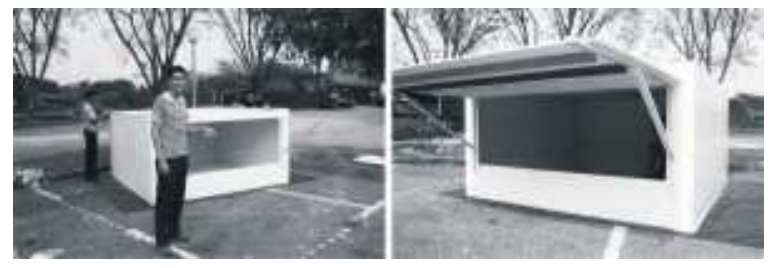

Fig. 1: Installation of scaled physical model on selected site
Experiment procedure: Three Reference Points (RP) were taken at work plane height $1 \mathrm{ft} .6$ in. $(450 \mathrm{~mm})$ : $\mathrm{RP}_{1}$ (4 $\mathrm{ft} . / 1200 \mathrm{~mm}$ from the aperture, center of the room), $\mathrm{RP}_{2}$ ( $7 \mathrm{ft} .7 \mathrm{in.} / 2275 \mathrm{~mm}$ from the aperture) and $\mathrm{RP}_{\mathrm{e}}$ (external illuminance), as shown in Fig. 3. Measurements of the 3 reference points were taken concurrently in order to calculate Daylight Factor (DF). Equipments used were Light Meter LX-100 (range 020000 lux) for indoor illumination and Photometer IL1400A (range 0-200000 lux) for external illuminance (Fig. 4).

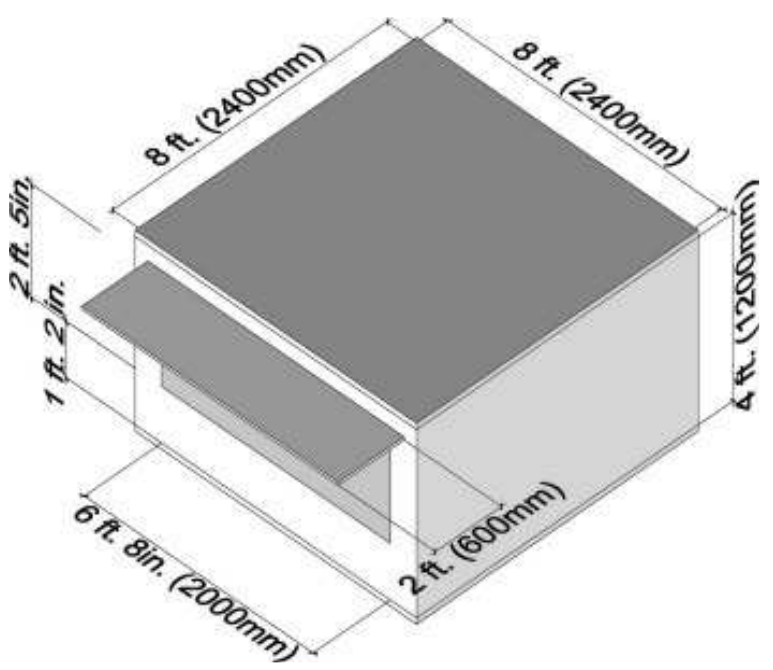

Fig. 2: Model for field measurement and computer simulation with scale $1: 2$

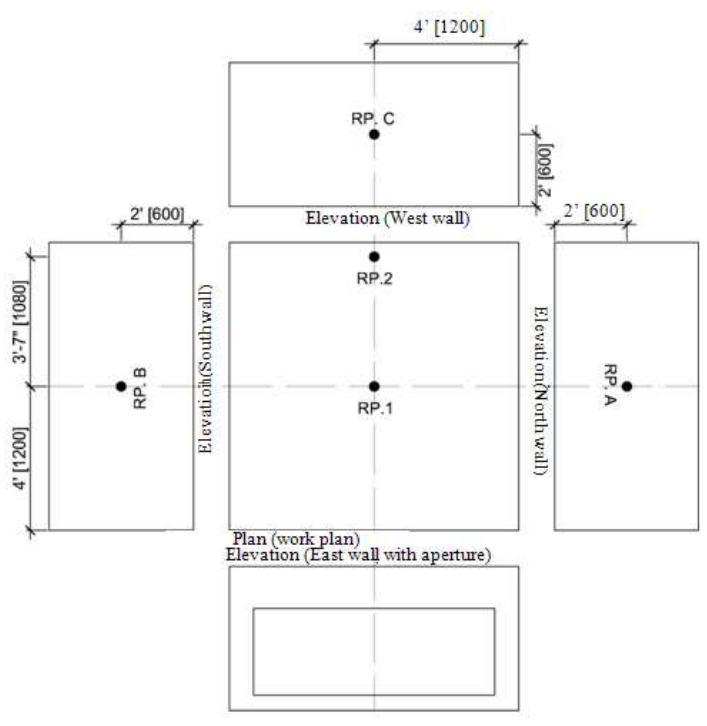

Fig. 3: Reference points for illuminance and luminance measurement 
Am. J. Applied Sci., 7 (10): 1426-1431, 2010

Table 1: Summary of test cases for field measurement and Desktop Radiance 2.0 simulation

\begin{tabular}{|c|c|c|c|c|c|}
\hline Test case & Date & Time & Sky Condition & Orientation & Overhang \\
\hline \multicolumn{6}{|c|}{ Field measurement } \\
\hline Measured 1 & 17 Nov 2009 & 0915-0925 & Overcast & East & No \\
\hline Measured 2 & 17 Nov 2009 & 0925-0935 & Overcast & East & $600 \mathrm{~mm}$ \\
\hline Measured 3 & 17 Nov 2009 & $1215-1225$ & Intermediate & East & No \\
\hline Measured 4 & 17 Nov 2009 & $1225-1235$ & Intermediate & East & $600 \mathrm{~mm}$ \\
\hline Measured 5 & 17 Nov 2009 & $1445-1455$ & Intermediate & East & No \\
\hline Measured 6 & 17 Nov 2009 & $1455-1505$ & Intermediate & East & $600 \mathrm{~mm}$ \\
\hline \multicolumn{6}{|c|}{ Computer simulation } \\
\hline Simulation 1 & 17 Nov 2009 & 0915 & CIE Overcast & East & No \\
\hline Simulation 2 & 17 Nov 2009 & 0925 & CIE Overcast & East & $600 \mathrm{~mm}$ \\
\hline Simulation 3 & 17 Nov 2009 & 1215 & CIE Intermediate & East & No \\
\hline Simulation 4 & 17 Nov 2009 & 1225 & CIE Intermediate & East & $600 \mathrm{~mm}$ \\
\hline Simulation 5 & 17 Nov 2009 & 1445 & CIE Intermediate & East & No \\
\hline Simulation 6 & 17 Nov 2009 & 1505 & CIE Intermediate & East & $600 \mathrm{~mm}$ \\
\hline
\end{tabular}

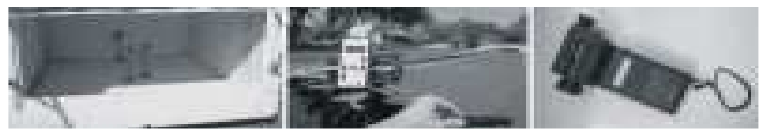

Fig. 4: Light Meter LX-100 (left) and Photometer IL1400A (middle), Luminance Meter Topcon BM9 (right)

Luminance Meter Topcon BM9 (Fig. 4) was used to measure the surface luminance. Three Reference Points (RP) were taken at the centre of the surfaces of the three internal walls: $\mathrm{RP}_{\mathrm{A}}$ (north wall), $\mathrm{RP}_{\mathrm{B}}$ (south wall) and $\mathrm{RP}_{\mathrm{C}}$ (west wall) as shown in Fig. 3.

Criteria of analysis: In order to validate the various performances of Desktop Radiance 2.0, several experiments were carried out:-

External illuminance $\left(\mathbf{E}_{\mathbf{e}}\right)$ : was measured and simulated for comparison in order to have a better understanding of the tropical sky and CIE sky characteristics.

Absolute Work Plan Illuminance (WPI): were measured and simulated at $\operatorname{RP}_{1}\left(e_{1}\right)$ and $\operatorname{RP}_{2}\left(e_{2}\right)$ for comparison as shown in Fig. 3. According to MS 1525: 2007 (Department of Standards Malaysia, 2007), the recommended minimum absolute WPI for general office is 300 lux.

DF: is defined as the ratio of interior illuminance on a horizontal surface $\left(E_{i}\right)$ to the exterior illuminance on a horizontal surface $\left(E_{e}\right)$ (Robbins, 1986). Only the measurements taken under overcast sky (test 1 and 2) were applicable for DF analysis

$\mathrm{DF}=\left(\mathrm{E}_{\mathrm{i}} / \mathrm{E}_{\mathrm{e}}\right) \times 100$

Absolute surface luminance: of $\mathrm{RP}_{\mathrm{A}}\left(\mathrm{L}_{\mathrm{A}}\right), \mathrm{RP}_{\mathrm{B}}\left(\mathrm{L}_{\mathrm{B}}\right)$ and $\mathrm{RP}_{\mathrm{C}}\left(\mathrm{L}_{\mathrm{C}}\right)$ were recorded for comparison.
Luminance ratio: is calculated as the ratio of one surface luminance value $\left(\mathrm{L}_{1}\right)$ to the adjacent surface luminance value $\left(\mathrm{L}_{2}\right)$. Luminance value of $\mathrm{RP}_{\mathrm{A}}\left(\mathrm{L}_{\mathrm{A}}\right)$ was used as a reference value to compare with luminance value of $\mathrm{RP}_{B}\left(\mathrm{~L}_{\mathrm{B}}\right)$ and $\mathrm{RP}_{\mathrm{C}}\left(\mathrm{L}_{\mathrm{C}}\right)$ :

$\mathrm{R} 1=\mathrm{L}_{\mathrm{A}} / \mathrm{L}_{\mathrm{B}}$

$\mathrm{R} 2=\mathrm{L}_{\mathrm{A}} / \mathrm{L}_{\mathrm{C}}$

Test cases: All tests were summarized in Table 1. Since this experiment intended to compare the measured and simulated results, all the tests were conducted only on east orientation. For further comparison, external overhang was employed to test the effect of overhang on the daylight performance. Hence, two cases were configured for each test: Without overhang and with $600 \mathrm{~mm}$ overhang.

\section{RESULTS}

Illuminance experiment: The measured external luminance under real tropical sky in Malaysian outdoor condition was much higher in comparison to the simulated data under CIE standard sky. Figure 5 shows that the highest external luminance was at the noon time (Test 3). The highest difference between the measured and simulation result was Test 6, (92.43\%); whereas the closest between the measured and simulation was Test $1(69.17 \%)$. External illuminance varies drastically during the experiment.

The external luminance directly influenced the absolute WPI. Therefore, the measured absolute WPI was also much higher than the simulated. As shown in Fig. 6, the measured results had all the reference points in the 6 tests fulfilled the minimum 300 lux recommendation. However, for the simulated results, only $25 \%$ fulfilled the recommendation. The highest difference between the two results was Test 3 RP1 (87.29\%); while the lowest was Test 2 RP2 (41.39\%). The mean difference was $71.06 \%$. 


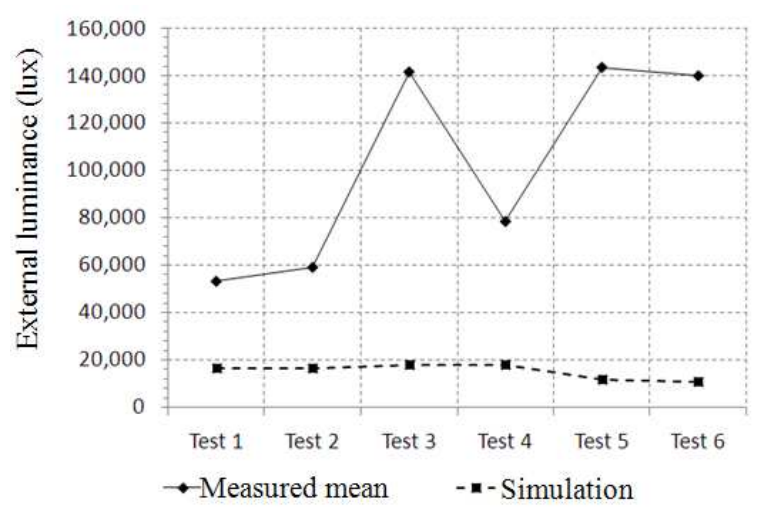

Fig. 5: Comparison of measured and simulated external illuminance

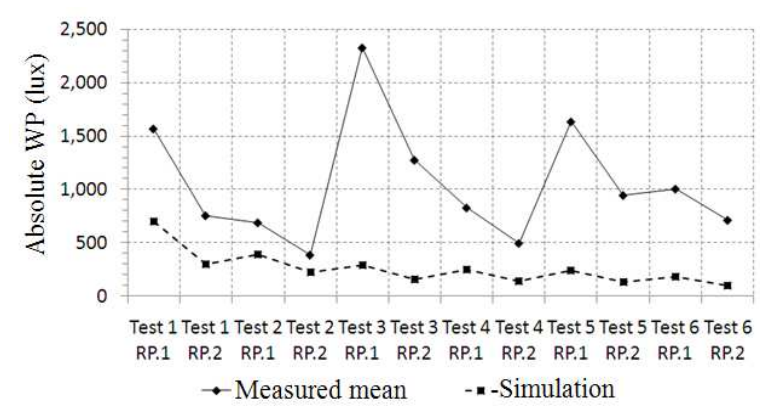

Fig. 6: Measured and simulated absolute WPI

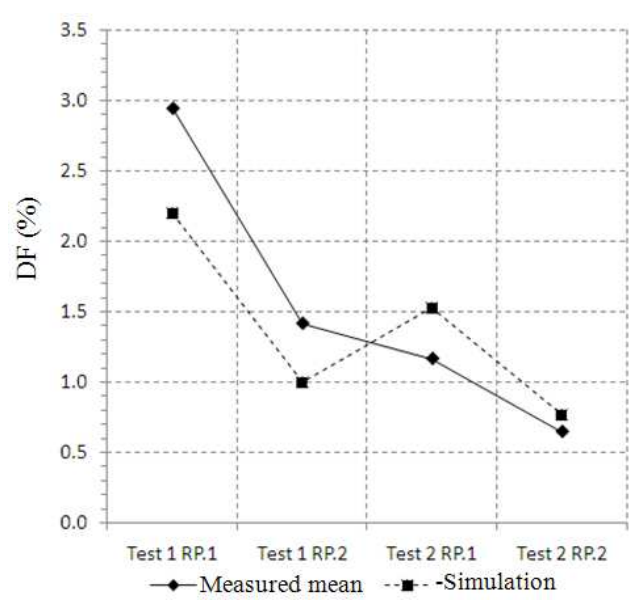

Fig. 7: Measured and simulated DF

Simulated DF result was close to the measured results (Fig. 7). The highest difference from the measured results was Test 2 RP1, 30.77\% higher; while the lowest was Test 2 RP2, $18.46 \%$ higher. The mean difference was $26.06 \%$ higher.

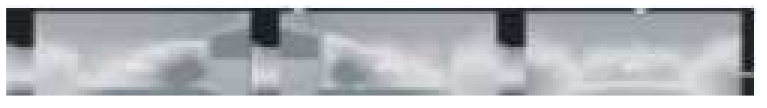

Fig. 8: Luminance false color for simulation 1

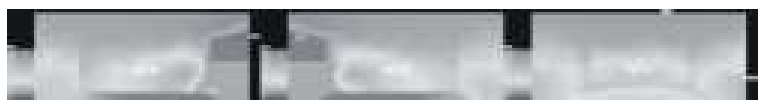

Fig. 9: Luminance false color for simulation 2

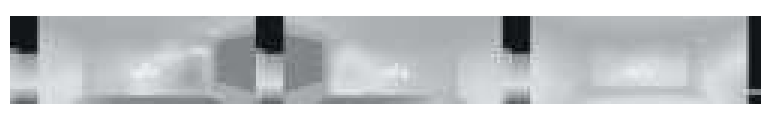

Fig. 10: Luminance false color for simulation 3

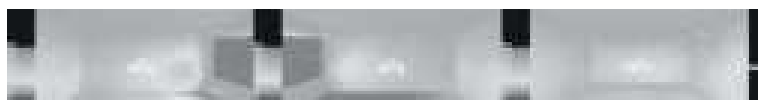

Fig. 11: Luminance false color for simulation 4

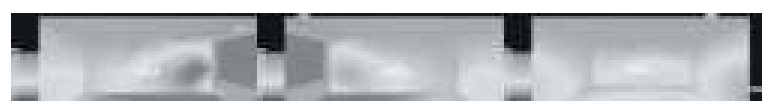

Fig. 12: Luminance false color for simulation 5

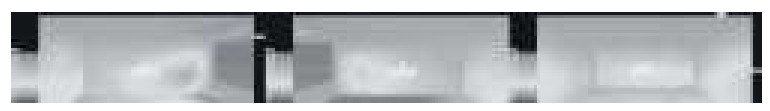

Fig. 13: Luminance false color for simulation 6

Luminance experiment: The Desktop radiance luminance false color for simulation 1-6 are shown in Fig. 8-13. The distribution of the colors shows the uniformity of the surface luminance. Glare occurred in Simulation 1 (Fig. 8) because the contrast of the surface luminance was drastic due to the direct sunlight patch through the east facing aperture. With the use of 600 $\mathrm{mm}$ overhang in Simulation 2, the direct sunlight patch was reduced and gives a more uniform distribution of daylight (Fig. 9). During noon and afternoon time (Simulation 3-6), the direct sunlight patch was not obvious except in Simulation 5. In all cases, the floor was brighter while the ceiling was darker. It also showed that $\mathrm{RP}_{\mathrm{A}}$ was always brighter than $\mathrm{RP}_{\mathrm{B}}$ and $R P_{C}$; while $R_{C}$ was brighter than $R_{B}$.

Due to the higher external luminance, the measured absolute surface luminance was higher than the simulated (Fig. 14). The highest differences of the simulated from measured results was Test $3 \mathrm{RP}_{\mathrm{A}}$, yielded $79.13 \%$ lower; while the lowest was Test 2 $\mathrm{RP}_{\mathrm{B}}$, with $3.62 \%$ higher. The mean difference was $49.71 \%$ lower. 
Am. J. Applied Sci., 7 (10): 1426-1431, 2010

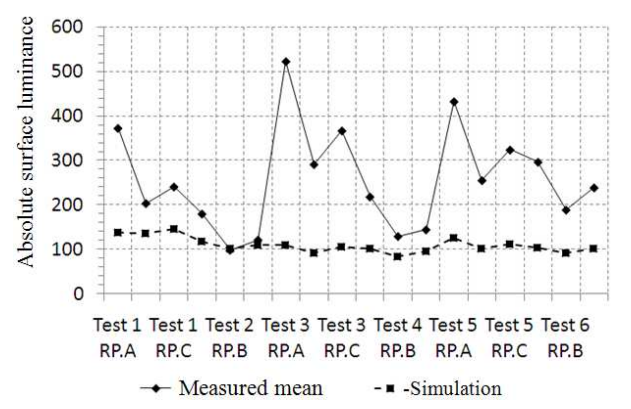

Fig. 14: Measured and simulation results for absolute surface luminance; test 1-6

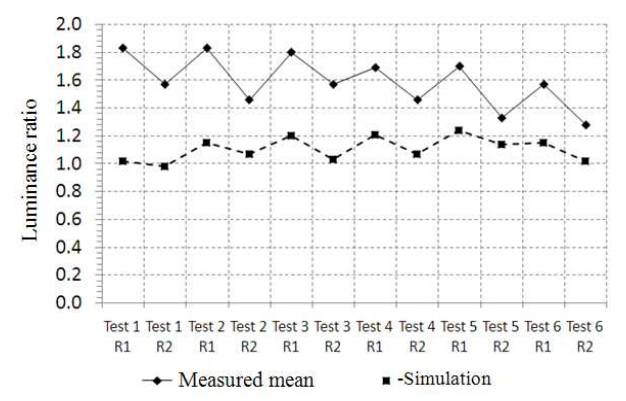

Fig. 15: Measured and simulation results for luminance ratio; test 1-6

Figure 15 shows the differences between the measured and simulated luminance ratio for $\mathrm{R} 1$ $\left(\mathrm{RP}_{\mathrm{A}} / \mathrm{RP}_{\mathrm{B}}\right)$ and $\mathrm{R} 2\left(\mathrm{RP}_{\mathrm{A}} / \mathrm{RP}_{\mathrm{C}}\right)$ for all test cases. Generally, it shows that $R_{1}$ was constantly higher than R2 for both measured and simulated results $\left(\mathrm{RP}_{\mathrm{A}}>\mathrm{RP}_{\mathrm{C}}>\mathrm{RP}_{\mathrm{B}}\right)$. The highest difference of the simulated results from the measured was Test $1 R_{1}$ (44.26\% lower) and the lowest was Test 5 R2 (14.29\% lower). The mean difference was $29.75 \%$ lower.

\section{DISCUSSION}

The simulation tool was unable to predict external illuminate close to the real Malaysian tropical sky condition. However, lower differences were recorded for simulation under CIE overcast sky (Test 1 and (2) in comparison to the CIE intermediate sky (Test 3-6). This is because the luminance distribution of the tropical sky during overcast sky is much more uniform.

Table 2 summarizes the differences of simulated results from measured results for various criteria. The high mean differences between the measured and simulated results in the external luminance, absolute WPI and absolute surface luminance conclude that it is inapplicable to use these simulation tools to predict the absolute luminance and luminance values. In order to simulate the daylight performance accurately, DF and luminance ratio are considered more comparable and reliable.
Table 2: Summary of the differences of simulated results from measured results

\begin{tabular}{lccc}
\hline & \multicolumn{2}{c}{ Differences (\%) } & \\
\cline { 2 - 4 } Criteria & \multicolumn{1}{c}{ Min } & Max & Mean \\
\hline External illuminance & 69.17 & 92.43 & 81.63 \\
Absolute WPI & 41.39 & 87.29 & 71.06 \\
DF & 18.46 & 30.77 & 26.06 \\
Absolute surface luminance & 3.62 & 79.13 & 49.71 \\
Luminance ratio & 14.29 & 44.26 & 29.75 \\
Average & & & 44.37 \\
\hline
\end{tabular}

\section{CONCLUSION}

This study presents an empirical comparison between the scaled physical model measurement and Desktop Radiance 2.0 simulation daylight performance results. The average mean difference between the measured and simulated results was $44.37 \%$. Due to the dissimilar characteristics between tropical sky and CIE sky models, relative ratios such as DF and luminance ratio are better choices to compare the performances. Factors that affect the accuracy of the performance in this study include the surrounding environment reflectance and landscape. For future research, validation on other parameters can be performed such as orientations, angle of the overhang, glazing, window sizes, colors, environment settings and electric lighting.

\section{ACKNOWLEDGEMENT}

This research project is funded by Initial Research Grant Scheme (IRGS), University Technology Malaysia (UTM) under grant Vot 78384 titled "Simplified Design Tool for Optimum External Shading towards Energy Efficiency in Hot Humid Tropic".

\section{REFERENCES}

Ander, G.D., 2003. Daylighting Performance and Design. 2nd Edn., Wiley, New Jersey, ISBN: 0471262994, pp: 336.

Arasteh, D., J. Carmody, E.S. Lee, S. Selkowitz and E. Lee, 2003. Window Systems for High Performance Buildings. 1st Edn., W.W. Norton and Company, New York, ISBN: 0393731219, pp: 356.

Department of Standards Malaysia, 2007: Malaysian standard: Code of practice on energy efficiency and use of renewable energy for non-residential buildings. Department of Standards Malaysia.

Dubois, M.C., 2001. Impact of shading devices on daylight quality in offices. Lund University. http://www.bkl.lth.se/fileadmin/byggnadskonstrukt ion/publications/Report3062.pdf 
Lim, Y.W., M.H. Ahmad and D.R. Ossen, 2008. Review on measuring tools for energy efficient solar shading strategies in tropical climate. J. Alam Bina, 14:

33-42. http://www.fab.utm.my/download/ConferenceSemi ar/JAB2008Jld14No5AR02.pdf

Linhart, F., S.K. Wittkopf and J.L. Scartezzini, 2010. Performance of anidolic daylighting systems in tropical climates-parametric studies for identification of main influencing factors. Solar Energy, $\quad 84$ : 1085-1094. DOI: 10.1016/j.solener.2010.01.014

Loutzenhiser, P.G., G.M. Maxwell and H. Manz, 2007. An empirical validation of the daylighting algorithms and associated interactions in building energy simulation programs using various shading devices and windows. Energy, 32: 1855-1870. DOI: 10.1016/j.energy.2007.02.005

Mahdavi, A., 2008. Predictive simulation-based lighting and shading systems control in buildings. Build Simulat., 1: 25-35. DOI: 10.1007/s12273008-8101-4
Mistrick, R.G., 2000. Desktop radiance overview? Pacific The Pennsylvania State University. http://radsite.lbl.gov/deskrad/drad-overview.pdf

Ossen, D.R., M.H. Ahmad and N.H. Madros, 2005. Optimum overhang geometry for building energy saving in tropical climates. J. Asian Archit. Build. Eng., $\quad 570$ : 563-570. http://www.jstage.jst.go.jp/article/jaabe/4/2/563/_p df

Robbins, C.L., 1986. Daylighting: Design and Analysis. 1st Edn., Van Nostrand Reinhold, New York, New Jersey, ISBN: 0442279493, pp: 877.

Xia, C., Y. Zhu and B. Lin, 2008. Building simulation as assistance in the conceptual design. Build. Simulat., 1: 46-52. DOI: 10.1007/s12273-0088107-y

Zain-Ahmed, A., K. Sopian, Z.Z. Abidin and M.Y.H. Othman, 2002. The availability of daylight from tropical skies-a case study of Malaysia. Renew. Energy, 25: 21-30. DOI: 10.1016/S09601481(00)00209-3 